\title{
OPTIMALISASI PERAN KADER REMAJA MELALUI PELATIHAN DAN DISKUSI INTERAKTIF TENTANG KENAKALAN REMAJA SEBAGAI ANTISIPASI DAMPAK NEGATIF PERKEMBANGAN TEKNOLOGI INFORMASI
}

\author{
OPTIMIZING THE ROLE OF YOUTH CADERS THROUGH INTERACTIVE TRAINING \\ AND DISCUSSION ON ADOLESCENT DISCUSSION AS AN ANTICIPATION OF THE \\ NEGATIVE IMPACT OF INFORMATION TECHNOLOGY DEVELOPMENT
}

Titik Sumiatin, Wahyu Tri Ningsih, Aby Yazid ABR, Roudlotul Jannah Poltekkes kemenkes Surabaya Prodi Keperawatan Tuban

Email : titiksumiatin1977@gmail.com

\begin{abstract}
ABSTRAK
Peningkatan angka kenakalan remaja saat ini menurut berbagai sumber sudah sangat memprihatinkan. Pencegahan perilaku beresiko pada remaja sangat dibutuhkan mengingat remaja merupakan masa dimana seseorang mencari jati diri dan identitas. Melalui kegiatan Posyandu, remaja memiliki wadah untuk mendapat pengetahuan tentang berbagai hal, mencari solusi masalah-masalah yang berhubungan dengan kesehatan dan sebagainya. Berdasarkan informasi dari bidan desa yang bertanggung jawab terhadap keberadaan dan keberlangsungan Posyandu Remaja di Desa Dawung Kecamatan Palang, kegiatan Posyandu semakin pasif, karena menurunnya minat remaja untuk menghadiri setiap acara yang digagas dan diadakan. Dari 517 remaja yang menjadi sasaran kegiatan Posyandu Remaja, hanya 50 remaja (9,6\%) yang hadir mengikuti kegiatan setiap bulannya.Dan dari 50 remaja yang hadir tersebut banyak yang ketika diajak berdiskusi, mereka justru terfokus pada Handphone atau gagdet yang di pegang. Melalui kegiatan ini peneliti ingin mengoptimalkan peran kader remaja melalui peningkatan pengetahuan dengan pelatihan dan diskusi interaktif kepada kader Posyandu remaja tentang kenakalan remaja sebagai dampak antisipasi negatif perkembangan teknologi Informasi, sebagai upaya untuk mencegah semakin meningkatnya perilaku beresiko pada remaja.
\end{abstract}

Kata kunci : Kader remaja, kenakalan remaja

ABSTRACT

According to various sources, the increase in juvenile delinquency rates is very concerning. Prevention of risky behavior in adolescents is needed, because adolescence was a period where someone was looking for identity. Through Posyandu activities, teenagers have a place to get knowledge about various things, looking for solutions to problems related to health and so on. Based on information from the village midwife who is responsible for the existence and sustainability of the Youth Posyandu in Dawung Village, Palang District, Posyandu activities are increasingly passive. because of the decreasing interest of teenagers to attend every event that was initiated and held. Of the 517 teenagers who were targeted by the Youth Posyandu, only 50 (9.6\%) attended the activity every month, And of the 50 teenagers who attended, when invited to discuss, they focused on the cellphone or gadget that was being held. Through this activity the researcher wants to optimize the role of youth cadres through increasing knowledge with training and interactive discussions with youth Posyandu cadres about juvenile delinquency as the impact of negative anticipation of the development of Information technology, as an effort to prevent the increasing risk behavior in adolescents.

Keywords: youth cadres, juvenile delinquency

\section{PENDAHULUAN}

Masalah remaja akhir akhir ini sudah sangat memprihatinkan. Disaat Indonesia telah merasa siap menyambut era globalisasi, di saat yang yang sama generasi penerus mendapat berbagai ancaman yang justru bisa melemahkan dan bahkan merusak pikiran dan semangat mereka. Masalah narkoba, Perkelahian, paham radikal, pergaulan bebas, 
kecanduan gajet, Pencurian, pembunuhan dan lain sebagainya.

Berdasarkan data Badan Statistik kriminal , tahun 2018 perkelahian massal selama setahun terakhir terus meningkat dari 3,26 persen desa/kelurahan pada tahun 2011 menjadi 3,38 persen desa/kelurahan pada tahun 2014, kemudian pada 2018 eningkat kembali menjadi 3,75 persen pada 2018. Kejahatan terkait narkotika (drugs) di Indonesia pada 2012 - 2016 cenderung meningkat. Namun, pada 2017 angkanya menurun. Kejadian kejahatan terkait narkotika tertinggi terjadi pada tahun 2016 sebesar 39.171 kasus dan pada 2017 dengan jumlah kasus sebanyak 35.142 kasus.

Kepala Badan Narkotika Nasional Provinsi Jawa Timur, Brigjen Pol Bambang Budi Santoso mengungkapkan hasil dari pelaksanaan institusi penerima wajib lapor (IPWL) di Klinik Utama BNNP Jatim. Hasilnya, sebanyak 51 persen pasien atau pemakai dan pecandu narkoba masih berusia anak atau remaja di bawah 19 tahun (Republika, 2018).

Kabupaten Tuban yang mendapat sebutan Bumi Wali, di tahun 2018 mengalami peningkatan yang signifikan yaitu sebanyak 52 kasus, dengan total jumlah tersangka kasus narkotika dan peredaran obat berbahaya selama 2018 mencapai 91 orang, dengan rincian 6 perempuan dan 85 tersangka laki-laki Bahkan Kapolres Tuban AKBP Nanang Haryono menyatakan tuban bisa dikatakan darurat Narkotika (blokTuban.com).

Hasil penelitian yang dilakukan oleh Hadi Purwanto dan kawan-kawan pada tahun 2015 didapatkan perilaku seks remaja dengan responden siswa SMA di Kabupaten Tuban adalah sebagai berikut, memegang tangan pacar/lawan jenis sejumlah 24 orang (83\%), berciuman di bibir yang melibatkan lidah sejumlah 24 orang $(8,3 \%)$, meraba bagian pribadi pasangan sebanyak 7 orang $(2,4 \%)$, diraba bagian pribadi Anda oleh pasangan sebanyak 11 orang $(3,8 \%)$, melakukan oral seks sejumlah 3 orang (1\%), dan melakukan hubungan seks sebanyak 4 orang $(1,4)$. Satu orang dari yang pernah melakukan hubungan seks melakukan pertama kali pada usia 9 tahun dan melakukannya dengan lebih dari 10 pasangan sampai saat pengambilan data.

Beberapa hal yang bisa dilakukan untuk mengatasi kenakalan Remaja diantaranya Kegagalan, yang mencapai identitas peran dan lemahnya kontrol diri bisa dicegah atau diatasi dengan prinsip keteladana, Adanya motifasi dari keluarga , guru, teman sebaya untuk melakukan point pertama, Kemauan orang tua untuk membenahi kondisi keluarga sehingga terciptakeluarga yang harmonis, komunikatif , dan nyaman bagi remaja, Remaja pandai memilih teman dan lingkungan yang baik serta orang tua memberi arahan dengan siapa dan dikomunitas mana remaja harus bergaul, Remaja membentuk ketahanan diri agar tidak terpengaruh, jika ternyata teman sebaya atau komunitas yang ada tidak sesuai dengan harapan.

Posyandu Remaja merupakan salah satu wadah yang bisa menampung berbagai aktivitas dan kegiatan remaja yang bernilai positif. Melalui Posyandu remaja, mereka bisa berkumpul, berdiskusi, bertukar pikiran dan pendapat, melakukan kegiatan sosial bersama dan lain sebagainya. Namun, fakta yang ada dilapangan keberadaan Posyandu remaja hanya ada secara fisik. Sedangkan fungsi dan kegunaannya tidak digunakan secara optimal dan sesuai harapan.

Berkembangnya arus teknologi dan informasi akhir-akhir ini mampu menggeser keberadaan Posyandu remaja sebagai salah satu wadah kegiatan remaja. Remaja tidak lagi tertarik dalam kegiatan bersama, namun mereka lebih tertarik berkumpul di warungwarung pinggir jalan yang memberikan fasilitas wifi gratis, sehingga mereka bisa bermain game bersama, hingga menghabiskan waktu berjam-jam hanya dengan duduk dan menggerakkan jari. Remaja lebih sering menghabiskan waktunya dengan gaget dan semakin minim bersosialisasi dengan sebayanya. Padahal sosialisasi justru sangat dibutuhkan di usia tersebut agar menunjang pertumbuhan dan perkembangaanya.

Posyandu Remaja di Desa Dawung Kecamatan Palang kabupaten Tuban, yang didirikan sejak tahun 2016 oleh Puskesmas Sumurgung, selama satu tahun terakhir juga mengalami penurunan aktivitas kegiatan . Berdasarkan informasi dari bidan desa yang bertanggung jawab terhadap keberadaan dan keberlangsungan Posyandu tersebut, kegiatan Posyandu semakin pasif, karena menurunnya minat remaja untuk menghadiri setiap acara yang digagas dan diadakan. Dari 517 remaja 
yang menjadi sasaran kegiatan Posyandu Remaja, hanya 50 remaja $(9,6 \%)$ yang hadir mengikuti kegiatan setiap bulannya.Dan dari 50 remaja yang hadir tersebut banyak yang ketika diajak berdiskusi, mereka justru terfokus pada Handphone atau gagdet yang di pegang.

Berdasarkan uraian latar belakang diatas maka kegiatan Pengabdian masyarakat melalui mProgram Kemitraan yang akan diselenggarakan oleh Dosen Poltekkes Kemenkes Surabaya Prodi Keperawatan Tuban bekerjasama dengan BNN (Badan Narkotika Nasional) Kabupaten Tuban dan Posyandu Remaja Desa Sumurgung ini diharapakan dapat membangkitkan kembali semangat dan motivasi kader-kader Posyandu remaja di Desa Dawung, sekaligus meningkatkan pengetahuan bagi kader tentang hal-hal yang berkaitan dengan masalah kenakalan remaja yang sedang menjadi tren issue akhir-akhir ini.

\section{METODE}

Kegiatan pengabdian masyarakat ini dilaksanakan dengan memberikan penjelasan, pemahaman dan diskusi interaktif tentang kenakalan remaja dan dampak negatif perkembangan teknologi informasi MELALUI METODE Luring dan Daring (PPT), mengingat dimasa Pandemi Covid ada protokol kesehatan yang harus dipatuhi yaitu Social distancing (Jaga jarak). Seluruh kader di beri modul sebagai panduan pelatihan sekaligus berisi materi-materi yang disampaikan nara sumber. Kegiatan ini dilaksanakan dengan harapan agar kader posyandu remaja dapat melakukan instropeksi diri tentang masalah yang saat ini dihadapi khususnya yang berhubungan dengan kenakalan remaja dan perilaku kecanduan gadget yang mungkin tidak disadari.

Sasaran pada kegiatan pengabdian masyarakat ini adalah seluruh kader Posyandu Remaja di Desa Dawung Kecamatan Palang Kabupaten Tuban, sebanyak 50 kader.

Kegiatan pertama diawali dengan mempersiapkan daftar hadir, banner, koordinasi dengan Puskesmas terkait, kepala desa dan ketua kader. Untuk pelaksanaan selanjutnya dilakukan perkenalan dan sosialisasi penggunaan gadget untuk mengikuti kegiatan secara on line/daring, selanjutnya dilakukan pre test, yang bertujuan untuk mengukur pengetahuan kader sebelum mengikuti kegiatan. Kemudian dilankutkan dengan penyampaian materi I dan II, secara of line dan on line (Seluruh peserta berkumpul di Balai desa, didampingi bidan desa, ketua kader dan Peneliti, sedangkan pemateri menyampaian materi secara on line dengan google meet). Diakhir sesi dilakukan diskusi dan tanya jawab, antara peserta dan pemateri. Kegiatan kedua dilankutkan dengan penyampaian materi ke III dan IV yaitu dari Badan Nasional Narkotika Kabupaten Tuban dan dari Puskesmas Sumurgung sebagai penanggung jawab. Diakhir sesi materi juga dilakukan diskusi dan tanya jawab serta pemaparan berbagai masalah aktual yang ada disekitar remaja yang berhubungan dengan kenakalan remaja dan dampak negatif perkembangan Teknologi informasi serta solusinya. Diakhir kegiatan hari ke II dilakukan Post test, sebagai evaluasi hasil pelaksanaan penyampaian materi. Dan Kegiatan ke tiga yaitu Luring (Tatap muka secara langsung dengan seluruh kader dan penanggng jawab kader, untuk embahas rencana tindak lanjut kegiatan Posyandu remaja setelah kegiatan Pengabdian masyarakat ini.

\section{HASIL DAN PEMBAHASAN}

Dari hasil kegiatan ini didapatkan kader kesehatan remaja sebelum dilakukan pelatihan sebagian adalah baik (50\%), dan masih ada yang berpengetahuan kurang $(10 \%)$ dan sangat kurang (2\%). Hal ini menunjukkan bahwa pengetahuan kader tentang kenakalan remaja sebagai antisipasi dampak negative perkembangan teknologi masih belum optimal, dikarenakan informasi yang pernah diterima tentang Kader Kesehatan Remaja, kenakalan remaja, NAPZA dan kecanduan Gadjet yang pernah diterima masih belum dipahami dengan benar atau mungkin sudah lupa, karena sudah lama. Setelah dilakukan pelatihan dan siskusi interaktif sebagian besar adalah sangat baik (78\%). Hal ini menunjukkan bahwa pengetahuan kader tentang kenakalan remaja sebagai antisipasi dampak negative perkembangan teknologi setelah dilakukan pelatihan selama 3 kali pertemuan mengalami peningkatan. Mereka lebih memahami tentang kenakalan remaja sebagai antisipasi 
dampak negative perkembangan teknologi daripada sebelum mengikuti pelatihan dan diskusi interaktif.

Tingkat pengetahuan kader Posyandu remaja juga dipengaruhi oleh tingkat pendidikan. Sebagian besar responden berpendidikan SMP dan SMA. Dari 50 kader 30 orang $(60 \%)$ berpendidikan SMA, 15 orang $(30 \%)$ berpendidikan SMP dan 5 orang (10\%) Perguruan tinggi. Pendidikan bisa berupa pengajaran keahlian khusus dan sesuatu yang mungkin tidak dapat dilihat tetapi lebih berarti. Pada umumnya semakin tinggi tingkat pendidikan maka akan semakin baik tingkat pengetahuan. (Notoatmodjo, 2011).

Selain pendidikan, pengetahuan juga dipengaruhi oleh aktif tidaknya kader mengikuti berbagai kegiatan Posyandu remaja, karena dalam stiap kegiatan ada hal yang baru yang didapatkan baik berupa pengetahuan, pengalaman maupun motivasi dari pembina.

\section{KESIMPULAN}

Kegiatan pengabdian masyarakat ini dapat meningkatkan pengetahuan kader Posyandu remaja tentang Kenakalan remaja, Napza dan Dampak negatif perkembangan Teknologi Informasi. Hal ini sesuai dengan tujuan awal diadaknnya kegiatan Pengabdian masyarakat, dimana kader Posyandu remaja memiliki pengetahuan yang lebih baik dibandingkan sebelum pelaksanaan kegiatan. Sehingga kedepan mereka mampu menyebarluaskan ilmu yang telah mereka dapatkan melalui media/jejaring sosial sesuai kondisi pandemi yang terjadi saat ini.

\section{DAFTAR PUSTAKA}

Badan Penelitian Dan Pengembangan Kesehatan Kementerian Kesehatan RI. (2010). Riset Kesehatan Dasar: Riskesdas 2010. Diakses 25 September 2012 dari Kementerian Kesehatan RI Badan Penelitian Dan Pengembangan Kesehatan Riset Kesehatan Dasar 2010 website

www.riskesdas.litbang.depkes.go.id/do wnload/TabelRiskesdas 2010.pdf

Badan Pusat Statistik (BPS), Badan Kependudukan dan Keluarga Berencana Nasional (BKKBN) dan Kementerian Kesehatan. (2012). Survei Demografi dan Kesehatan
Indonesia: Kesehatan Reproduksi Manusia Laporan Pendahuluan. Februari 2012.

Badan Koordinasi Keluarga Berencana Nasional. (2008). Modul Pelatihan Konseling Kesehatan Reproduksi Remaja Bagi Calon Konselor Sebaya. Direktorat Remaja dan Perlindungan Hak-Hak Reproduksi, Jakarta: BKKBN.

Bimo Walgito, Kenakalan Anak, (Yogyakarta: Yayasan Penerbitan Fakultas Psikologi, 1982)

BNN, LIPI (2018). Executive Summary Survey Penyalahgunaan dan Peredaran Gelap Narkoba Tahun 2018. Diakses dari https://ppid.bnn.go.id/wpcontent/uploads/sites/2/2019/02/hasil_1 it_bnn_2018.pdf

Centers for Disease Control and Prevention. (2013). Methodology of the Youth Risk Behavior Surveillance System 2013. Morbidity and Mortality Weekly Report,62, 1-18.

CNN Indonesia, Kamis 31 Oktober 2019 pukul 11.01

Jurnal Penelitian \& PPM ISSN: 2442-448X Vol 4, No: 2 Hal: 129 - 389 Juli 2017 349

Kemenkes RI. (2018). Buku KIE Kader Kesehatan Remaja. Jakarta: Kementerian Kesehatan RI

Kartini Kartono, Kenakalan Remaja, (Jakarta: PT. Raja Grafindo Persada, 1998)

Gaster, Volume XVI No 2 Agustus 2018

Lestary, Heny \& Sugiharti (20110 Perilaku Berisiko Remaja Di Indonesia Menurut Survey Kesehatan Reproduksi Remaja Indonesia (SKRRI) Tahun 2007; Jurnal Kesehatan Reproduksi Vol. 1 No 3, Agustus 2011 : 136- 144

Notoadmodjo S (2011). Kesehatan Masyarakat. Jakarta. Rinneke Cipta

Nunik Kusumawardani, dkk (2016). Perilaku Berisiko Kesehatan Pada Pelajar SMP Dan SMA Di Indonesia: Hasil Survey Nasional Kesehatan Berbasis Sekolah di Indonesia, Puslitbang Upaya Kesehatan Masyarakat Badan Litbangkes Kementerian Kesehatan RI

Syaiful Bahri Djamarah \& Aswan Zain, (2005), StrategiBelajarMengajar, Jakarta: PT. Rineka Cipta. 